\title{
Amniotic fluid disorders and the effects on prenatal outcome: a retrospective cohort study
}

H. Bakhsh ${ }^{1,2^{*}}$, H. Alenizy ${ }^{1,2}$, S. Alenazi $i^{3}$ S. Alnasser ${ }^{3}$, N. Alanazi ${ }^{3}$, M. Alsowinea ${ }^{3}$, L. Alharbi ${ }^{3}$ and B. Alfaifi ${ }^{3}$

\begin{abstract}
Background: The amniotic fluid is a protective liquid present in the amniotic sac. Two types of amniotic fluid disorders have been identified. First refers to polyhydramnios, which is an immoderate volume of amniotic fluid with an Amniotic Fluid Index (AFI) greater than $24 \mathrm{~cm}$. Second includes oligohydramnios, which refers to decreased AFI i.e., less than $5 \mathrm{~cm}$. This study aims to; a) identify the maternal risk factors associated with amniotic fluid disorders, b) assess the effect of amniotic fluid disorders on maternal and fetal outcome c) examine the mode of delivery in pregnancy complicated with amniotic fluid disorders.

Methods: A comparative retrospective cohort study design is followed. Sample of 497 pregnant women who received care at King Abdullah bin Abdul-Aziz University Hospital (KAAUH) between January 2017 to October 2019 was included. Data were collected from electronic medical reports, and was analyzed using descriptive statistics. Association of qualitative variables was conducted by Chi-square test, where $p$-value $<0.05$ was considered statistically significant.
\end{abstract}

Results: Among the collected data, 2.8\% of the cases had polyhydramnios and $11.7 \%$ patients had oligohydramnios. One case of still born was identified. A statically significant association was found between polyhydramnios and late term deliveries $(P=0.005)$ and cesarean section (CS) rates $(P=0.008)$. The rate of term deliveries was equal in normal AFI and oligohydramnios group $(P=0.005)$. Oligohydramnios was mostly associated with vaginal deliveries $(P=0.008)$. Oligohydramnios and polyhydramnios were found to be associated with diabetes mellitus patients $(P=0.005)$, and polyhydramnios with gestational diabetes patients $(P=0.052)$. Other maternal chronic diseases showed no effect on amniotic fluid index, although it might cause other risks on the fetus.

Conclusion: Diabetes mellitus and gestational diabetes are the most important maternal risk factors that can cause amniotic fluid disorders. Maternal and fetal outcome data showed that oligohydramnios associated with gestational age at term and low neonatal birth weight with high rates of vaginal deliveries, while polyhydramnios associated with gestational age at late term and high birth weight with higher rates of CS.

Keywords: Amniotic fluid, Disorders, Parental outcome, Saudi Arabia

\footnotetext{
* Correspondence: drobgyn2005@gmail.com

'Clinical Sciences Department, College of Medicine, Princess Nourah bint Abdulrahman University, Riyadh, Saudi Arabia

${ }^{2}$ Department of Obstetrics \& Gynecology, King Abdullah bin Abdulaziz University Hospital, Riyadh, Saudi Arabia

Full list of author information is available at the end of the article
}

(c) The Author(s). 2021 Open Access This article is licensed under a Creative Commons Attribution 4.0 International License, which permits use, sharing, adaptation, distribution and reproduction in any medium or format, as long as you give appropriate credit to the original author(s) and the source, provide a link to the Creative Commons licence, and indicate if changes were made. The images or other third party material in this article are included in the article's Creative Commons licence, unless indicated otherwise in a credit line to the material. If material is not included in the article's Creative Commons licence and your intended use is not permitted by statutory regulation or exceeds the permitted use, you will need to obtain permission directly from the copyright holder. To view a copy of this licence, visit http://creativecommons.org/licenses/by/4.0/ The Creative Commons Public Domain Dedication waiver (http://creativecommons.org/publicdomain/zero/1.0/) applies to the data made available in this article, unless otherwise stated in a credit line to the data. 


\section{Background}

The amniotic fluid is the protective liquid present in the amniotic sac, and mainly composed of water and solids, including proteins, carbohydrates, lipids and phospholipids, enzymes, hormones and chemical substances urea, uric acid, creatinine, electrolytes. It is developed from the membrane plasma by the development of fetus and serves as a protective cushion for the growing fetus. It has antibacterial properties to protect the growing fetus from infection, also it facilitates the exchange of nutrients, water and biochemical products between mother and fetus. Different types of fetal cells are further present which includes; skin, respiratory, intestinal, urinary tract and stem cells, hair and blood cells, all of which aid in the growth of fetus.

Amniotic Fluid Volume (AFV) does not change significantly from day to day, but generally it increases with the growth of fetus reaching a peak at 34 weeks of gestation (over $800 \mathrm{~mL}$ ), after which it may start to decrease [1]. However, in certain cases Amniotic Fluid Index (AFI) of the amniotic fluid volume is greater than $24 \mathrm{~cm}$, the phenomenon is referred as polyhydramnios [2]. Risk factors of polyhydramnios includes: maternal diabetes, fetal heart failure, abnormal swallowing and congenital infection [3]. The degree of increase in the AFV is directly associated with the increase in adverse risk factors on mother and fetus prenatally. Some of these prenatally outcomes include preterm birth, cesarean delivery [4], placental abruption, fetal malposition, macrosomia, umbilical cord prolapse and maternal respiratory compromise [2].

In contrast, AFI of the amniotic volume less than $5 \mathrm{~cm}$ is referred as oligohydramnios [5]. Risk factors of oligohydramnios includes: premature rupture of membranes, intrauterine growth restriction and birth defects [3]. Oligohydramnios impede normal fetal movement, retarded fetal growth and development leading towards fetal deformities, umbilical cord compression, while in some cases death may happen depending on gestational age. In the first trimester decrease in AFI is an ominous finding, the fetus usually undergo abortion. However, in the second trimester the prognosis majorly depends mostly on the etiology, borderline/low normal amniotic fluid volume which generally have a good prognosis, on the other hand severe oligohydramnios often lead to fetal death [6]. Whereas, in the third trimester many cases of oligohydramnios are idiopathic. The occurrence of a threatening fetal outcome is related to the umbilical cord compression, utro-placental insufficiency and meconium aspiration [5].

Amniotic Fluid Volume (AFV) reflects the state of pregnancy and possible adverse complications and outcome, due to which assessment of AFV has been part of every second and third trimester ultrasound examination. There are three standard methods for AFV assessment, first includes qualitative and other two are semiquantitative. Qualitative assessment is the first step in which the ultrasonographer subjectively report if the pregnancy is normal, oligo or polyhydramnios. With experienced examiners, the quality of the test can be equal to the semiquantitative tests [single deepest pocket (SDP), amniotic fluid index (AFI)] which are performed when there is an abnormality found in the qualitative test, specifically among patients with increased risk of pregnancy complications and patients in third trimester. Both SDP and AFI are good indicators for normal AFV. However, AFI overly diagnose oligohydramnios, and SDP overly diagnose polyhydramnios.

Due to the observed increase in cases of poly and oligohydramnios, this study estimated the effect of amniotic fluid disorders on prenatal outcome and reassess the reasons associated with it in Saudi Arabia. Besides, the relationship between maternal demographics and its effect on amniotic fluid disorders in Saudi Arabia are further observed.

\section{Specific objectives}

1. To identify the maternal risk factors associated with amniotic fluid disorders.

2. To assess the effect of amniotic fluid disorders on maternal and fetal outcome.

3. To identify the mode of delivery in pregnancy complicated with amniotic fluid disorders.

\section{Methods}

This study followed a comparative retrospective cohort study design. Patients who received care at a secondary hospital i.e., King Abdullah Bin Abdul-Aziz University Hospital (KKAUH) in its obstetrics \& gynecology department between January 2017-October 2019 were included. The study was approved by the institutional review board in Princess Nourah bint Abdulrahman University's (PNU) collage of medicine.

The electronic medical reports of normal and abnormal obstetrical ultrasound examinations reviewed during the study period were searched. These ultrasounds were taken as part of routine check-up or when prescribed by the consulted physician. Patients were included in the cohort, if they had at least one scan conducted by expert radiologists in our ultrasound unit.

A formulated data collection sheet was filled from each patient file without any intervention. Which included the following: demographic data, past medical history, past surgical history, obstetrics \& gynecology history, intraoperative complications, postoperative complications and neonatal outcomes. Neonatal outcomes encompass living status, gender, APGAR score, birth weight, admission of baby and congenital malformations. 
The cohort was stratified into three groups based on AFI: normal AFI, polyhydramnios (AFI $\geq 24 \mathrm{~cm}$ ), oligohydramnios $(\mathrm{AFI} \leq 5 \mathrm{~cm})$. The gestational age of pregnancy at the time of delivery was considered as the gestational week for measurement. The analysis excluded multiple pregnancy, because in multiple pregnancy, chronicity is important for perinatal outcomes. Since the number of multiple pregnancies was minimal it would have been difficult to know the effect of chronicity on outcomes.

Patients having mild case polyhydramnios or oligohydramnios were rarely given intervention. However, with moderate and severe cases options like amniotic fluid drainage or pharmacological intervention, the patient's consent and physician's assessment of the scenario varied. Patients with gestational diabetes were given treatment to treat it which in many cases also helped in resolving polyhydramnios or oligohydramnios.

The statistical analysis was done using Statistical Package of Social Sciences (SPSS). Descriptive statistics in terms of frequency and percentages was used to describe criteria of studied sample. Association of qualitative variables was conducted by chi-square test. $P$-value less than 0.05 will be considered as statistically significant. Confidentiality of the collected data was ensured, and the information was only used for scientific research purposes. The methodology adhered to the STROBE guidelines which can be seen in supplementary Table 1 .

\section{Results}

Medical records of 597 patients were reviewed in this study, among them 453 (91.1\%) were Saudis, around 388 (78\%) were $\leq 35$ years old. About $288(57.9 \%)$ of the maternal BMI scores were $\geq 30$. Around $124(24.9 \%)$ of the patients were primigravida, however $373(75.1 \%)$ of them were multigravida. Chronic medical illnesses were reported around 74 (14.8\%). These patients were also getting adequate treatment for their chronic diseases, specifically in cases when there's high risk of pregnancy or mother's health being affected. Majority of the cases i.e., 425 (85.5\%) had normal amniotic fluid index (AFI). However, 14 (2.8\%) had polyhydramnios, and 58 (11.7\%) had oligohydramnios (Table 1).

The results (Table 2) showed that almost half of the neonate were boys 246 (49.5\%), and the other half were girls 251 (50.5\%). Only one case still born was identified $0.2 \%$, while $496(99.8 \%)$ were born alive. Majority of the patients were delivered at term $424(85.3 \%)$, whereas, other $31(6.2 \%)$ and $42(8.5 \%)$ had a preterm and late term delivery respectively. The APGAR score of $<7$ at 1 min and 5 mins interval was found in 3 and 2 children respectively. About 405 (81.6\%) of them were admitted to nursery and the rest $91(18.3 \%)$ were admitted to
Table 1 Demographic Data of the Mothers (Frequency)

\begin{tabular}{|c|c|c|}
\hline Variable & $\begin{array}{l}\text { Frequency } \\
\text { (N) }\end{array}$ & $\begin{array}{l}\text { Percentage } \\
\text { (\%) }\end{array}$ \\
\hline \multicolumn{3}{|l|}{ Nationality } \\
\hline Saudi & 453 & $91.1 \%$ \\
\hline Non-Saudi & 44 & $8.9 \%$ \\
\hline \multicolumn{3}{|l|}{ Age } \\
\hline$\leq 35$ (less than or equal 35$)$ & 388 & $78 \%$ \\
\hline > 35 (more than 35) & 109 & $22 \%$ \\
\hline \multicolumn{3}{|l|}{ Years of Education } \\
\hline School & 2 & $0.4 \%$ \\
\hline University & 14 & $2.8 \%$ \\
\hline Unknown & 481 & $96.8 \%$ \\
\hline \multicolumn{3}{|l|}{ Work status } \\
\hline Housewife & 7 & $1.4 \%$ \\
\hline Employee & 14 & $2.8 \%$ \\
\hline Student & 12 & $2.4 \%$ \\
\hline Unknown & 464 & $93.4 \%$ \\
\hline \multicolumn{3}{|l|}{ BMI } \\
\hline$<25$ (normal and underweight) & 48 & $9.7 \%$ \\
\hline 25-29.9 (overweight) & 161 & $32.4 \%$ \\
\hline$\geq 30$ (obese) & 288 & $57.9 \%$ \\
\hline \multicolumn{3}{|l|}{ Gravity } \\
\hline Primigravida & 124 & $24.9 \%$ \\
\hline Multigravida & 373 & $75.1 \%$ \\
\hline \multicolumn{3}{|l|}{ Chronic Medical IIIness } \\
\hline Hypertension & 3 & $0.6 \%$ \\
\hline Diabetes mellitus & 8 & $1.6 \%$ \\
\hline Heart disease & 2 & $0.4 \%$ \\
\hline Renal disease & 0 & $0.0 \%$ \\
\hline Bronchial asthma & 16 & $3.2 \%$ \\
\hline Hypothyroidism & 45 & $8.9 \%$ \\
\hline \multicolumn{3}{|l|}{ Amniotic Fluid Index } \\
\hline Normal & 425 & $85.5 \%$ \\
\hline Polyhydramnios & 14 & $2.8 \%$ \\
\hline Oligohydramnios & 58 & $11.7 \%$ \\
\hline
\end{tabular}

NICU. While, the congenital anomalies were diagnosed in $31(6.3 \%)$ of neonates.

There is no significant association between maternal age and the occurrence of amniotic fluid disorders. Amniotic fluid disorders found to be higher in multigravida and BMI group $\geq 30$ with non-significant $P$-value. A statically significant association was found between gestational age at delivery and amniotic fluid disorders, polyhydramnios with late term deliveries. Besides, the rate of term deliveries was equal in normal AFI and oligohydramnios group $(P=0.005)$. However, the rate of 
Table 2 Frequency of Neonatal Outcome

\begin{tabular}{|c|c|c|}
\hline Variable & Frequency & Frequency (\%) \\
\hline \multicolumn{3}{|l|}{ Gender } \\
\hline Girl & 251 & $50.5 \%$ \\
\hline Boy & 246 & $49.5 \%$ \\
\hline Total & 497 & $100 \%$ \\
\hline \multicolumn{3}{|l|}{ Living status } \\
\hline Live born & 496 & $99.8 \%$ \\
\hline Still born & 1 & $0.2 \%$ \\
\hline Neonatal death & 0 & $0.0 \%$ \\
\hline Total & 497 & $100 \%$ \\
\hline \multicolumn{3}{|l|}{ Gestational age } \\
\hline Preterm $<37$ weeks & 31 & $6.2 \%$ \\
\hline Term $\geq 37-41$ weeks & 424 & $85.3 \%$ \\
\hline Late term $\geq 42$ weeks & 42 & $8.5 \%$ \\
\hline \multicolumn{3}{|l|}{ Admission of baby } \\
\hline Nursery & 405 & $81.6 \%$ \\
\hline $\mathrm{NICU}$ & 91 & $18.3 \%$ \\
\hline \multicolumn{3}{|l|}{ Congenital anomalies } \\
\hline Yes & 31 & $6.3 \%$ \\
\hline No & 465 & $93.7 \%$ \\
\hline Total & 496 & $100 \%$ \\
\hline \multicolumn{3}{|l|}{${ }^{\mathrm{a}}$ APGAR score } \\
\hline$<7$ at $1 \mathrm{~min}$ & 3 & $0.6 \%$ \\
\hline$<7$ at $5 \mathrm{~min}$ & 2 & $0.4 \%$ \\
\hline
\end{tabular}

amissing 4 cases

caesarean section (CS) was higher among pregnancies complicated with polyhydramnios, and oligohydramnios was found to be majorly associated with vaginal deliveries $(P=0.008)$. Oligohydramnios was associated with neonatal birth weight $<2.5 \mathrm{~kg}$ and $>2.5 \mathrm{~kg}$, and polyhydramnios was associated with neonatal birth weight $\geq 2.5$ $\mathrm{Kg}(P<0.01)$. Cardiovascular and renal congenital anomalies were diagnosed in neonates with polyhydramnios and oligohydramnios respectively with a non-significant $P$-value. (Table 3).

Results in Table 4 indicate a remarkable significant association between oligo and polyhydramnios and patients with diabetes mellitus $(P=0.005)$, and gestational diabetes patients $(P=0.052)$. However, there was no significant association between oligo or polyhydramnios and hypertension, heart disease, bronchial asthma, hypothyroidism and anemia.

\section{Discussion}

The above results were based on the data obtained from the electronic medical records of 597 patients admitted in the department of obstetrics and gynecology at KAAUH, during January 2017 to October 2019.
According to the results, $14.8 \%$ of the sample had different chronic medical illness, where $75.1 \%$ were multigravida. Besides, $14(2.8 \%)$ of the sample were diagnosed as polyhydramnios and 58 (11.7\%) of the cases were oligohydramnios based on their amniotic fluid index. Regarding the mode of delivery, 10 (71.4\%) of polyhydramnios cases required caesarean section, and almost all cases of abnormal amniotic fluids showed no significant association with congenital malformation. The most significant maternal risk factors associated with amniotic fluid disorders include diabetes mellitus and gestational diabetes.

Majority of the mothers had live born neonates, and only single case $(0.2 \%)$ of stillbirth was documented with no obvious reason due to the lack of data. Similarly, a study conducted at King Abdul-Aziz University Hospital in Jeddah showed that 5356 out of 5432 patients enrolled in the study had liveborn neonates, which represented 98.6\% [7], this difference in percentage might be due to the large sample size enrolled in their study in comparison to the enrolled sample used in this research. More than $20 \%$ neonates of total deliveries got admitted in NICU due to various medical reasons such as lower APGAR score or congenital anomalies, out of which $18.3 \%$ of 496 liveborn neonates were admitted to NICU that were included in this study. Here, $6.2 \%$ of total babies were diagnosed with congenital anomalies, $22.6 \%$ of them were cardiovascular, while $54.8 \%$ were renal. Although, no relation was established with amniotic fluid disorders, the percentage is significantly higher compared to the previous study where 160 out of 5432 (2.9\%) babies were diagnosed with congenital malformations [7].

In the present study, the maternal age was divided into two age groups i.e. participants less or equal to 35 years, and participants with above 35 years of age. However, most of the study participants $(77.4 \%)$ were below 35 years, and the occurrence of amniotic fluid disorders was the same compared to the other age group (22.6\%) of above or equal to 35 years. Thus, no association was found between maternal age and amniotic fluid disorders. Corresponding to another study done in Ondokuz Mayis University, Turkey, maternal age has no effect on perinatal and neonatal outcomes [8].

A statically significant association was found between gestational age at delivery and amniotic fluid disorders, polyhydramnios cases were mostly associated with late term deliveries which defined as a delivery after 42 weeks of gestation $(P=0.005)$, while the rate of term deliveries was equal in normal AFI and oligohydramnios group. These results are in contrast with another research conducted in Spain, which stated that oligohydramnios and polyhydramnios cases were associated with shorter gestational age [9] It could be due to the mild cases of polyhydramnios or successful treatment that the mothers underwent. 
Table 3 Association Between the Types of Amniotic Fluids

\begin{tabular}{|c|c|c|c|c|c|}
\hline & & $\begin{array}{l}\text { Normal AFI } \\
\mathrm{N}(\%)\end{array}$ & $\begin{array}{l}\text { Polyhydramnios } \\
\text { N (\%) }\end{array}$ & $\begin{array}{l}\text { Oligohydramnios } \\
\mathrm{N}(\%)\end{array}$ & $P$-value \\
\hline \multirow[t]{2}{*}{ Maternal age } & $\leq 35$ & $329(77.4 \%)$ & $9(64.3 \%)$ & $50(86.2 \%)$ & 0.14 \\
\hline & $>35$ & $96(22.6 \%)$ & $5(35.7 \%)$ & $8(13.8 \%)$ & \\
\hline \multirow[t]{2}{*}{ Maternal parity } & Primigravida & $105(24.7 \%)$ & $3(21.4 \%)$ & $16(27.6 \%)$ & 0.85 \\
\hline & Multigravida & $320(75.3 \%)$ & $11(78.6 \%)$ & $42(72.4 \%)$ & \\
\hline \multirow[t]{3}{*}{$B M I$} & $<25$ & $44(10.3 \%)$ & $0(0.0 \%)$ & $4(6.9 \%)$ & 0.76 \\
\hline & $25-29.9$ & $138(32.5 \%)$ & $4(28.6 \%)$ & $19(32.8 \%)$ & \\
\hline & $\geq 30$ & $243(57.2)$ & $10(71.4 \%)$ & $35(60.3 \%)$ & \\
\hline \multirow[t]{3}{*}{ Gestational age at delivery } & Preterm < 37 weeks & $21(5.0 \%)$ & $2(14.3 \%)$ & $8(13.8 \%)$ & 0.005 \\
\hline & Term 37-41 weeks & $366(86.1 \%)$ & $9(64.3 \%)$ & 49 (84.5\%) & \\
\hline & Late term $\geq 42$ & $38(8.9 \%)$ & $3(21.4 \%)$ & $1(1.7 \%)$ & \\
\hline \multirow[t]{2}{*}{ Admission of baby } & $\begin{array}{l}\text { Nursery } \\
405\end{array}$ & $352(83.0 \%)$ & $9(64.3 \%)$ & $44(75.9 \%)$ & 0.11 \\
\hline & $\begin{array}{l}\mathrm{NICU} \\
91\end{array}$ & $72(17.0 \%)$ & $5(35.7 \%)$ & $14(24.1 \%)$ & \\
\hline \multirow[t]{4}{*}{ Mode of delivery } & Vaginal & $256(60.2 \%)$ & $2(14.3 \%)$ & $36(62.1 \%)$ & 0.008 \\
\hline & Instrumental & $19(4.5 \%)$ & $2(14.3 \%)$ & $2(3.4 \%)$ & \\
\hline & Emergency CS & $78(18.4 \%)$ & $5(35.7 \%)$ & $14(24.1 \%)$ & \\
\hline & Elective CS & $72(16.9 \%)$ & $5(35.7 \%)$ & $6(10.3 \%)$ & \\
\hline \multirow[t]{5}{*}{ Neonatal birth weight } & $<1 \mathrm{~kg}$ & $4(0.9 \%)$ & $0(0.0 \%)$ & $1(1.7 \%)$ & $<0.01$ \\
\hline & $1-1.4$ kg & $10(2.4 \%)$ & $0(0.0 \%)$ & $4(6.9 \%)$ & \\
\hline & $1.5-2.4 \mathrm{~kg}$ & $19(4.5 \%)$ & $0(0.0 \%)$ & $10(17.2 \%)$ & \\
\hline & $2.5-4 \mathrm{~kg}$ & $365(86 \%)$ & $12(85.7 \%)$ & $38(65.5 \%)$ & \\
\hline & $>4 \mathrm{~kg}$ & $26(61.3 \%)$ & $2(14.3 \%)$ & $5(8.6 \%)$ & \\
\hline \multirow[t]{4}{*}{ Congenital malformation } & No anomaly & $398(93.8 \%)$ & $12(85.7 \%)$ & $55(94.8 \%)$ & 0.16 \\
\hline & Cardiovascular & $11(2.6 \%)$ & $2(14.3 \%)$ & $0(0.0 \%)$ & \\
\hline & Neurological & $1(0.2 \%)$ & $0(0.0 \%)$ & $0(0.0 \%)$ & \\
\hline & Renal & $14(3.3 \%)$ & $0(0.0 \%)$ & $3(5.2 \%)$ & \\
\hline
\end{tabular}

Among our collected sample, the rate of cesarean deliveries was higher in polyhydramnios cases comparing to normal cases, as mentioned by Yefet \& Daniel-Spiegel [10] that, "This was attributed to an increased rate of elective surgeries because of suspected macrosomia". In addition, the rate of vaginal deliveries was greater among oligohydramnios cases. These results are in contrast with those proposed by a research conducted in India which stated that the rate of vaginal deliveries was second highest after cesarean deliveries [11]. Also, 14 cases of

Table 4 Association Between Past Maternal History or chronic illness with Polyhydramnios and Oligohydramnios

\begin{tabular}{lllll}
\hline Past Medical History & $\begin{array}{l}\text { Normal AFI } \\
\text { N (\%) }\end{array}$ & $\begin{array}{l}\text { Polyhydramnios } \\
\text { N (\%) }\end{array}$ & \multicolumn{2}{l}{$\begin{array}{l}\text { Oligohydramnios } \\
\text { N (\%) }\end{array}$} \\
\hline Hypertension & $2(0.5 \%)$ & $1(7.1 \%)$ & $0(0 \%)$ & $2(3.4 \%)$ \\
Diabetes mellitus & $4(0.9 \%)$ & $2(14.3 \%)$ & 0.116 \\
Heart disease & $2(0.5 \%)$ & $0(0 \%)$ & $2(3.4 \%)$ & 1 \\
Bronchial asthma & $13(3 \%)$ & $1(7.1 \%)$ & $4(6.9 \%)$ & 0.005 \\
Gestational Diabetes mellitus & $43(10.1 \%)$ & $4(28.6 \%)$ & $6(10.3 \%)$ & 0.052 \\
Hypothyroidism & $38(8.9 \%)$ & $1(7.1 \%)$ & $1(1.7 \%)$ & 0.902 \\
Anemia & $14(3.3 \%)$ & $1(7.1 \%)$ & $1(1.7 \%)$ & 0.517 \\
Other & $40(9.4 \%)$ & $2(14.3 \%)$ & 0.072 \\
\hline
\end{tabular}


polyhydramnios and 43 cases of oligohydramnios neonates weighted more than or equal to $2.5 \mathrm{Kg}$, whereas, 15 (25.9\%) cases of oligohydramnios neonates were 2.5 $\mathrm{Kg}$ or less than it. A highly considerable association was found between polyhydramnios cases and neonates who weighted $\geq 2.5 \mathrm{~kg}$. However, most of the neonates who weighted $<2.5 \mathrm{~kg}$ were diagnosed as oligohydramnios. Same association was found in a previous research which proved that the amniotic fluid disorders are mostly associated with lower birth weight [9].

No obvious relation was established between high body mass index (BMI above 25) and amniotic fluid disorders. Besides, more than half of the sample were obese 57.9, and $32.4 \%$ were overweight. Correspondingly, another research conducted in 2016 revealed that KSA is considered as the 15th most obese country with rate of $33.7 \%$ among population, thus no relation can be established [12]. However, there were increased cases of poly and oligohydramnios and congenital anomalies in this study, this could be because majority of them are obese or overweight as maternal obesity is linked to pregnancy complications and neonatal outcomes [13].

It has been noted that the occurrence of polyhydramnios was highly related to chronic disease of diabetes mellitus with $P$-value equal to 0.005 . Similar value was shown with mothers who suffered from gestational diabetes mellitus, as outlined in one of the relevant articles that the most notable maternal risk factor behind polyhydramnios is diabetes mellitus [3] which was also associated with the cases represented oligohydramnios. Hence, it can be said that past maternal history of diabetes mellitus is the main risk factor behind amniotic fluid disorders according to the research outcome. Other maternal chronic diseases showed no effect on amniotic fluid index although it might cause other risks on the fetus. Similarly, no association was found between hypertensive disorder of pregnancy and oligohydramnios, which could be due to the mild cases or treatment received by the mothers.

This study has important implications, as the findings may help medical experts in providing proper counselling regarding pregnancy related complications found among most of the Saudi women. It will further help medical experts to consider all the risk factors associated to the amniotic fluid disorders and its impact on maternal and fetal outcome. These findings may serve as highly useful in reducing the risks associated to the amniotic fluid disorders [14]. The study was limited as it was a single center study. Also, the effects of treatment for chronic conditions of mothers and its impact on the amniotic fluid disorder was not studied due to the availability of limited data.

\section{Conclusion}

Findings of this study confirms that maternal risk factors which were associated with amniotic fluid disorders included diabetes mellitus and gestational diabetes. Regarding the maternal and fetal outcomes, the results indicated that oligohydramnios associated with gestational age at term and neonatal birth weighted $<2.5 \mathrm{~kg}$, and polyhydramnios associated with gestational age at late term and neonatal birth weighted $>2.5 \mathrm{Kg}$. Regarding the mode of delivery, it was found that CS was higher among pregnancies which were complicated due to polyhydramnios while oligohydramnios was mostly associated with vaginal deliveries.

\section{Supplementary Information}

The online version contains supplementary material available at https://doi. org/10.1186/s12884-021-03549-3.

Additional file 1. STROBE Statement-Checklist of items that should be included in reports of retrospective studies.

\section{Abbreviations}

AFI: Amniotic Fluid Index; AFV: Amniotic Fluid Volume; BMl: Body Mass Index; CS: Cesarean Section; KAAUH: King Abdullah bin Abdul-Aziz University Hospital; NICU: Neonatal Intensive Care Unit; PNU: Princess Nourah bint Abdulrahman University; SDP: Single Deepest Pocket; SPSS: Statistical Package of Social Sciences

\section{Acknowledgements}

The authors are very thankful to all the associated personnel in any reference that contributed in/for the purpose of this research.

\section{Authors' contributions}

All authors have approved the manuscript. H. Bakhsh: correspondence, conception, design, analysis, administration and editing. H. Alenizy: Analysis and writing. S. Alenazi: Analysis and writing. S. AlNasser: Analysis and writing. N. Alanazi: Analysis and writing. M. Alsowinea: Analysis and writing. L. Alharbi: Analysis and writing. B. Alfaifi: Analysis and writing.

\section{Funding}

This research is not funded by any resource.

\section{Availability of data and materials}

The datasets used and analyzed during the current study are available from the corresponding author on reasonable request.

\section{Ethics approval and consent to participate}

The study has been declared by the institutional review board in Princess Nourah bint Abdulrahman University (PNU), college of medicine. The study is registered under IRB \# KACST-KSA: H-01-R-059 [IRB Log No. 19-0222]. No licenses or permissions are required.

\section{Consent for publication}

Not applicable.

\section{Competing interests}

The authors declare no competing interest.

\section{Author details}

${ }^{1}$ Clinical Sciences Department, College of Medicine, Princess Nourah bint Abdulrahman University, Riyadh, Saudi Arabia. ${ }^{2}$ Department of Obstetrics \& Gynecology, King Abdullah bin Abdulaziz University Hospital, Riyadh, Saudi Arabia. ${ }^{3}$ College of Medicine, Princess Nourah bint Abdulrahman University, Riyadh, Saudi Arabia. 
Received: 24 June 2020 Accepted: 8 January 2021

Published online: 22 January 2021

\section{References}

1. Ross MG, Beall MH. Physiology of amniotic fluid volume regulation [Internet]. teksmedik.com. 2018. https://teksmedik.com/uptodate19/d/topic. htm?path=physiology-of-amniotic-fluid-volume-regulation. Accessed $26 \mathrm{Mar}$ 2020.

2. Beloosesky R, Ross MG. Polyhydramnios [Internet]. 2018. https://teksmedik. com/uptodate19/d/topic.htm?path=polyhydramnios. Accessed 26 Mar 2020

3. Amniotic Fluid Problems/Hydramnios/Oligohydramnios. Children's Hospital of Philadelphia. https://www.chop.edu/conditions-diseases/amniotic-fluidproblemshydramniosoligohydramnios. Accessed 26 Mar 2020.

4. Mathew M, Saquib S, Rizvi SG. Risk factors and outcome. Saudi Med J. 2008; 29(2):256-60.

5. Beloosesky R, Ross MG. Oligohydramnios. 2018 https://teksmedik.com/ uptodate19/d/topic.htm?path=oligohydramnios. Accessed 26 Mar 2020.

6. Morris RK, Meller CH, Tamblyn J, Malin GM, Riley RD, Kilby MD, Robson SC, Khan KS. Association and prediction of amniotic fluid measurements for adverse pregnancy outcome: systematic review and meta-analysis. Bjog: Bjog-Int J Obstet Gy. 2014;121(6):686-99. https://doi.org/10.1111/1471-0528. 12589.

7. Fida NM, Al-Aama J, Nichols W, Alqahtani M. A prospective study of congenital malformations among live born neonates at a university hospital in western Saudi Arabia. Saudi Med J. 2007;28(9):1367.

8. Cakmak Celik F, Aygun C, Kucukoduk S, Bek Y. Maternal and neonatal outcomes in advanced maternal age: a retrospective cohort study. J Matern-Fetal Neo M. 2017;30(20):2452-6. https://doi.org/10.1080/14767058. 2016.1253058

9. Martínez-Frías ML, Bermejo E, Rodríguez-Pinilla E, Frías JL. Maternal and fetal factors related to abnormal amniotic fluid. J Perinatol. 1999;19(7):514-20.

10. Yefet E, Daniel-Spiegel E. Outcomes from polyhydramnios with normal ultrasound. Pediatrics. 2016;137(2):e20151948. https://doi.org/10.1542/peds. 2015-1948.

11. Madhavi K, Rao PC. Clinical study of oligohydramnios, mode of delivery and perinatal outcome. IOSR J Dent Med Sci. 2015;14(4):6-11.

12. Alqarni M. A review of prevalence of obesity in Saudi Arabia. J Obes Eat Disord. 2016;2(2):25. https://doi.org/10.21767/2471-8203.100025.

13. Timur BB, Timur H, Tokmak A, Isik H, Eyi EG. The influence of maternal obesity on pregnancy complications and neonatal outcomes in diabetic and nondiabetic women. Geburtshilfe Frauenheilkd. 2018;78(4):400. https:// doi.org/10.1055/a-0589-2833.

14. Magann E, Ross MG. Assessment of amniotic fluid volume. 2018. https:// teksmedik.com/uptodate19/d/topic.htm?path=assessment-of-amniotic-fluidvolume Accessed 26 Mar 2020.

\section{Publisher's Note}

Springer Nature remains neutral with regard to jurisdictional claims in published maps and institutional affiliations.

\section{Ready to submit your research? Choose BMC and benefit from:}

- fast, convenient online submission

- thorough peer review by experienced researchers in your field

- rapid publication on acceptance

- support for research data, including large and complex data types

- gold Open Access which fosters wider collaboration and increased citations

- maximum visibility for your research: over $100 \mathrm{M}$ website views per year

At $\mathrm{BMC}$, research is always in progress.

Learn more biomedcentral.com/submissions 